\title{
Hyperbaric oxygen therapy for central retinal artery occlusion; combined triple technique for upper lid cicatricial entropion
}

In this issue, Yip et $\mathrm{al}^{1}$ share with us the outcome of hyperbaric oxygen therapy for central retinal artery occlusion. Among the 25 patients with central retinal artery occlusion aged 44 to 89 years, hyperbaric oxygen therapy was provided after a mean onset-to-therapy time of 13.3 \pm 7.4 (range, 4.4-32.2) hours. The visual result was encouraging, in particular among the four younger patients aged $\leq 50$ years whose final vision was hand movement $(\mathrm{F} / 45), 0.7(\mathrm{~F} / 48), 0.8(\mathrm{~F} / 50)$, and $0.7(\mathrm{~F} / 44)$. It seems that younger patients with central retinal artery occlusion have a more favorable prognosis after hyperbaric oxygen therapy. Readers look forward to data of longer follow-up in a larger patient group in the future.

Another original article in this issue is about the surgical management of upper lid cicatricial entropion. Although trachoma is rarely seen in Hong Kong, upper lid cicatricial entropion still occurs in older patients. This debilitating disease can be challenging to treat as recurrence is common after surgery. Chan et $\mathrm{al}^{2}$ describe their combined triple technique of upper eyelid blepharoplasty, tarsal margin rotation, and posterior lamellar super-advancement for cicatricial entropion correction. Dissection through scarred tissue planes in cicatricial eyelids can be difficult and bloody, but the authors take on the challenge to tackle pathologies at both the anterior and posterior lamellae once and for all.
One would expect a prolonged surgery with such intricacy, yet the mean operation time was $<1$ hour. Despite being a pilot study, the long-term results were encouraging. It would be interesting to further explore the learning curve of the surgery and the outcome in a larger sample.

Multiple-choice questions related to the above two articles are designed to provide CME credits for Fellows of the Hong Kong Academy of Medicine. Fellows can only complete the CME questions online at https://www.icmecpd.hk/ for immediate credit of the points, as the old hard copy method would not be provided starting from this issue.

\section{Alvin KH Kwok, ${ }^{1} M D(H K), M D(C U H K), P h D(H K)$, FRCS (UK), FRCOphth (UK), FHKAM (Ophth), PostGrad DipEpidem \& Biostat (CUHK), MBBS (HK); Alvin KH Au, ${ }^{2}$ MHM (UNSW), FHKAM (Ophth) \\ ${ }^{I}$ Department of Ophthalmology, The Hong Kong Sanatorium and Hospital, Hong Kong \\ ${ }^{2}$ Department of Ophthalmology and Visual Sciences, Prince of Wales Hospital, Hong Kong}

Correspondence and reprint requests:

Dr Alvin KH Kwok, Department of Ophthalmology, 4/F, Li Shu Fan Block, The Hong Kong Sanatorium and Hospital, 2 Village Road, Hong Kong.

Email:alvinkhkwok@netvigator.com

\section{References}

1. Yip LT, Au SCL, Ko CKL. Hyperbaric oxygen therapy for central retinal artery occlusion: experience in Hong Kong. Hong Kong J Ophthalmol 2020;24:44-50. Crossref
2. Chan KKW, Li CL, Chan RYC, Young AL, Yip WWK, Chong $K K L$. Upper eyelid blepharoplasty, tarsal margin rotation, and posterior lamellar super-advancement for correction of severe upper eyelid cicatricial entropion and dermatochalasis. Hong Kong J Ophthalmol 2020;24:38-43. Crossref 